\title{
BRIDGING THE GAP BETWEEN INFRASTRUCTURE CAPACITY ALLOCATION AND MARKET-ORIENTED RAILWAY: AN ALGORITHMIC APPROACH
}

\author{
Nikola STOJADINOVIĆ ${ }^{\star}$, Branislav BOŠKOVIĆ, Mirjana BUGARINOVIĆ \\ Dept of Railway Transport, Faculty for Transport and Traffic Engineering, University of Belgrade, Belgrade, Serbia
}

Received 6 September 2018; revised 19 November 2018, 1 April 2019, 4 May 2019; accepted 24 May 2019;

first published online 10 September 2019

\begin{abstract}
The European Commission initiated the process of liberalization and introducing competition in the European railway sector more than twenty-five years ago. Despite the liberalization of the railway sector, train paths are currently administratively allocated in all EU countries using the train service priority criterion, which may not treat all train operators equally. This is especially evident in those network sections where demand exceeds the available capacity. In these situations, economic theory suggests the implementation of a market-based mechanism for allocation of capacity, such as auctions. However, due to its incompatibilities with priority criteria in the process of capacity allocation, it is necessary to develop a new procedure to support the implementation of an auction. In this paper, the proposed algorithm fills the technological gap between train timetable design and train operator requests. The new algorithm for decentralized capacity allocation is the result of a multidimensional approach, which encompasses setting new relations between train operators and the infrastructure manager, train timetable drafting and resolving the conflicting request. In addition, the algorithm provides a feasible solution ensuring equal treatment of train operators and efficient allocation, in order to foster the development of the competition in the European rail market.
\end{abstract}

Keywords: railway capacity allocation, decentralized approach, train path auction, railway market, timetable design, technological gap.

\begin{abstract}
Abbreviations
IM - infrastructure manager;

PSO - public service obligation;

TOC - train operator company;

$\mathrm{TP}$ - train path.
\end{abstract}

\section{Introduction}

In 1991, the European Commission decided to open up the rail market. The open rail market means that there is direct competition among TOCs, in order to ensure better quality and more competitive railway services at lower prices for end-users. Today, in nearly all EU member states, in addition to incumbents ${ }^{1}$, a large number of private TOCs provide passenger and freight transport services.

\footnotetext{
${ }^{1}$ The term "incumbents" is used here to refer to successors to a historical railway undertaking, i.e. the TOCs that emerged from the former monopolist as a result of the restructuring process. The majority shareholder in most of these TOCs is still the state.
}

However, despite its decision that enables open access competition, the European Commission did not change the traditional TP allocation procedure, used in the era of the monopolistically organized railway system. Under the traditional procedure, timetables are designed using priority criteria based on the type of transport service (Caprara et al. 2007). From the aspect of TOCs, even though the rail market officially opened up, their position in the timetable design procedure is determined in advance by priority criteria based on the type of service they provide (Borndörfer et al. 2006). This makes it impossible for TOCs providing different services on infrastructure to compete for TPs. The decision to ensure competition in this market is not compatible with the traditional way of TP allocation, which fails to treat all train service categories and, consequently, different TOCs as their providers in a fair and equitable manner (Luan et al. 2017). In other words, even though the rail market is open to competition, there is still no TP market (Perennes 2017).

${ }^{\star}$ Corresponding author. E-mail: n.stojadinovic@sf.bg.ac.rs 
The emergence of competition in the rail sector made it necessary to introduce mechanisms for setting access charges for TPs (Kozan, Burdett 2005) and resolving conflicting path requests. Previous studies also indicate that for variety of reasons, the traditional TP allocation procedure has had a significant impact on the slowdown of the development of competition in the market setting for a number of reasons, starting from inadequate priority criteria in the market conditions (Bassanini et al. 2002; Nilsson 2015), the system's slow response to market requirements (Brewer, Plott 1996), to time-consuming process of timetable design (Burdett, Kozan 2010; Nilsson 2015). Finally, it has made it possible for inefficient incumbents to keep their dominant share in the market (Beria et al. 2012). Moreover, a tendency to go on applying the traditional TP allocation procedure enables incumbents to keep the best TPs in the timetable (Bergantino et al. 2015). According to the 2016 figures $^{2}$, the incumbents' share in the freight transport market amounted to more than $85 \%$ in $12 \mathrm{EU}$ member states. However, the incumbents' share in the passenger transport market amounted to more than $80 \%$ in $22 \mathrm{EU}$ member states. Thus, there is a reason to believe that the allocation of railway infrastructure capacity should better reflect train operators' request (influenced by end-users) rather than pre-defined train priority criteria, which deprive the market as we know it today of its purpose. It is, therefore, necessary to make a shift from what is evidently a centralized approach of path allocation, based on the administrative mechanism of path allocation, to a new, market-oriented approach, which will boost competition on the network.

The allocation of railway infrastructure capacity using the traditional priority rules in the circumstances of competition between train operators is a problem particularly evident on congested infrastructure sections. The congestion of railway infrastructure from the economic point of view can be defined as the increased demand for paths on a network section, which exceeds its available capacity during certain periods (Bassanini et al. 2002). From the technical perspective, the congestion arises from conflicting path requests, which occurs when two trains reserving the same block of the infrastructure within the same point in time, is called block conflict (Schlechte 2012). In order to meet one path request, another path request has to be altered or excluded (Nash 2005). In such cases, conflicting path requests are dealt with using the defined priority criteria, which is usually not related to market requirements or market-based operation.

In contrast to the traditional priority rules, whenever the conflicting demand exists, in the last forty years the new approaches starting to be sought such as marketbased mechanisms, i.e. auctions. The first idea of auction usage in transport came from Rassenti et al. (1982), who considered combinatorial auction implementation for allocation of airport slots in New York (US). In order to

\footnotetext{
${ }^{2}$ According to achieved passenger-kilometres and tonne-kilometres (Eurostat 2018).
}

enable the use of auctions for path allocation in practice, there has to be a TP allocation procedure or algorithm to coordinate the requirements of railway timetable design with the use of auctions. Moreover, the rail sector needs an algorithm, which clearly defines the phases and the roles of TOCs and the IM in the auction-based TP allocation process. In view of the specific features of the open rail market, it is necessary to design the algorithm in which auctions can be used, to define the roles of TOCs and the IM in auction-based capacity allocation, as well as to mitigate the negative effects inherent in the auction mechanism.

The aim of this paper is to design and propose a TP allocation algorithm, in order to support further development of the railway market. The authors suggest a new perspective in addressing the path allocation problem as well as a comprehensive solution, i.e. a new algorithm, which is (1) based on decentralized path allocation and (2) relying on the auction mechanism for resolving conflicting path requests. The new algorithm is the result of a systemic approach to the problem of coordinating the goals and limitations of the auction mechanism with the specific features of train timetable design.

In this respect, the paper examines the current $\mathrm{TP}$ allocation procedure and priority criteria used by the EU member states, as well as the problems encountered in applying the procedure (Chapter 1). Chapter 2 contains the basic idea of decentralized capacity allocation and the literature review dealing with the possibility of using auctions for TP allocation from the viewpoint of transport policy. Chapter 3 defines the basic requirements the new TP allocation algorithm has to meet. In the same chapter, we define the basic algorithm phases and give a more detailed description of the algorithm design with the focus on the role of participants in the allocation process. The last chapter includes conclusions.

\section{Background of the capacity allocation problem on railways}

\subsection{Current practice: "yesterday and today"}

Before the reform of the rail sector, only a national railway company had to deal with the problem of railway infrastructure capacity allocation. As a monopolist, it was in charge of both infrastructure management as well as providing transport services. The planning of the transport offer for all types of services was coordinated by different units of the only railway company at the time. Timetable design $^{3}$ was an instrument of coordination of the technical constraints of available infrastructure capacity and rolling stock with transport needs. The coordination of supply and demand was aimed at maximizing the utilization of

\footnotetext{
${ }^{3}$ In this paper, the term "timetable design" primarily means TP allocation, i.e. defining the trains' time and place of departure and arrival, as well as their stops along the route. In rail transport, a TP can be defined as a description of railway infrastructure usage in place and time (Pachl 2009).
} 
railway capacity from the technical and transport quality aspects. At the same time, due to its protected position and ownership structure, a national railway undertaking did not have to use infrastructure efficiently, so that economic goals had secondary importance. As a result, timetable design i.e. TP allocation was treated as a strict engineering problem rather than an economic problem (Brewer, Plott 1996).

In the era of the monopolistically organized railway system, the allocation of paths in timetable design was based on predefined train hierarchy (or train rank). By belonging to a specific train category, each train automatically held a specific status that meant having priority over or being subordinate to other train categories in the process of timetable design as well as real-time traffic management. When creating the timetable, this practically meant that paths were first allocated (drawn on a train timetable graph ${ }^{4}$ ) to top priority trains, whereas the paths of other, lower-rank train categories had to be adjusted to the paths already drawn on the graph. If a conflict between two trains of the same rank emerged, a national railway company appointed a special internal commission to solve the problem using its experience and intuition. The term used in the literature to describe such an approach is an administrative mechanism (Nilsson 2002).

In the past when IMs and TOCs were integrated into one single company the TP requests for railway capacity were either already coordinated due to the train timetabling or the occurring conflicts were easy to resolve since the information about all related planning steps of railway operation was available (Klabes 2010). In practice, the approach works as follows: to design the timetable, the previous timetable is used as a basis and then adjusted to the new requests to be incorporated in the new timetable. Generally, this is a centralized approach to timetable design and TP allocation, which means that a single authority plays the main, decisive role in timetable design from the point of its drafting to conflict resolution (Brewer, Plott 1996).

Following the opening up of the railway market, the problem of timetable design became more complex. This is primarily due to the fact that a company offering infrastructure capacity (paths), namely the IM, and companies buying paths, namely TOCs, are now separate entities. Due to the emergence of a high number of TOCs in the market, the IM is faced with an uncoordinated demand for paths (Klabes 2010). As the number of TOCs and their path requests grows, the number of conflicting requests potentially rises. As a result, the IM is increasingly faced with the decision, which requests should be given priority.

Adopting Directive 2001/14/EC, the European Commission defined the legal framework for railway infra-

\footnotetext{
${ }^{4}$ Train timetable graph (or traffic diagram) is a graphic description of train movements. The amount of traffic on a railway line is described in form of a time-distance diagram, that consists of a time axis and distance axis. Train movements are represented by TPs on a time-distant graph with a train description inscribed on them (Pachl 2009).
}

structure capacity allocation in the EU member states (EC 2001). The Directive allows the member states to adopt their own legal frameworks for capacity allocation and to define specific priority rules, but they have to make sure that the capacity is allocated to TOCs in an equitable man$n e r^{5}$. IMs are responsible for capacity allocation, provided that they are independent of any TOC in their decisionmaking (EC 2012) ${ }^{6}$. If not, a separate independent body should be in charge of the procedure. The European Commission also defined two new procedures to resolve potential conflicts between path requests.

Figure 1 shows the capacity allocation algorithm of the current regulatory framework, with the procedures encircled with a dashed line representing the changes resulting from Directive 2012/34/EU (EC 2012) ${ }^{7}$. The TP allocation process starts with the submission of a TOC's path request to the IM. The IM should try to meet all requests by TOCs as much as possible. It should try to reconcile conflicting requests using the extended tolerances stated by a TOC in its path request (Klabes 2010). Once a draft timetable is released, the IM presents it to all TOCs that have to submit their requests. TOCs have a one-month deadline to submit to the IM their objections to the draft timetable.

If it is not possible to find a solution without the active involvement of TOCs, the IM initiates the coordination procedure (highlighted in Figure 1) by holding consultations. If the coordination procedure, which cannot exceed one month, does not result in a solution, TOCs have one more chance to submit a complaint against the proposed timetable. The dispute resolution procedure (highlighted in Figure 1) should result in a solution within 10 working days maximum (EC 2012).

If conflicting requests cannot be dealt with using the two above procedures, the IM declares congestion on a given infrastructure section. If access charges for congestion have not been introduced or are not giving satisfactory results, the IM can give priority to specific services in the timetable, which will be only in force on the infrastructure section where congestion has been declared. Moreover, the criterion used to determine priority has to take into account the importance of service to society relative to any other service, which will be excluded in this way (EC 2012). Priority criteria to be used if congestion on an infrastructure section is declared must be published in the IM's network statement. In practice, this means that the IM continues to apply the centralized approach of path allocation; however, the publication of the criteria makes

\footnotetext{
${ }^{5}$ Article 10 of Directive 2012/34/EU (EC 2012);

${ }^{6}$ Although the IM should act independently of any TOC when making decisions, in practice it still acts in "collusion" with the incumbent, especially when it operates as part of a holding company. The incumbent can come into possession of the confidential information of its competitors in the market during the TP allocation procedure (Woodburn 2014). For this reason, the EU proposed in its Fourth Railway Package of 2016 (EC 2019) that IMs be completely separate from other holding company entities and that the so-called "Chinese walls" be put in place around them;
} 


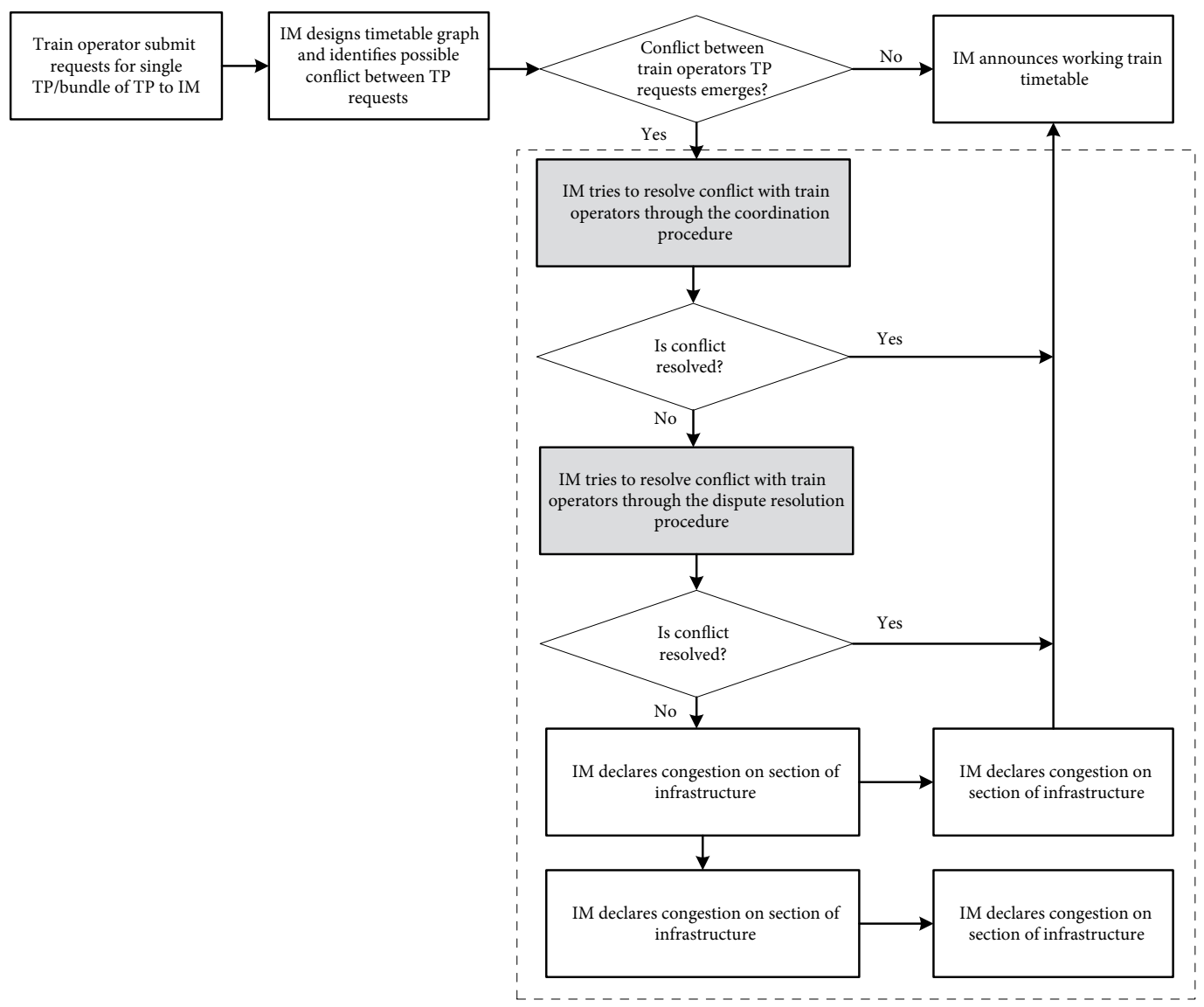

Figure 1. Algorithm for capacity allocation with procedures for solving conflict demand based on Directive 2012/34/EU (EC 2012) (source: research by authors)

the whole process somewhat more transparent.

\subsection{A case study: priority criteria for congested railway infrastructure in EU member states}

Directive 2001/14/EC allows the EU member states to develop path allocation priority criteria independently and without any limitations (EC 2001). Therefore, the room has been created for the diversification of criteria in priority giving. To this end, an overview of the used priority criteria, published in the network statements of the EU member states, Norway and Switzerland included ( 24 countries in total), has been made (Table 1$)^{8}$. The priority criteria (Table 1 , column 1 ) are listed as ranked in network statements, while column 2 shows the number of countries using the relevant criterion. One should bear in mind that some countries do not have all train service categories, which reflects on how frequently they appear.

In all EU member states, the published priority criteria can be systematized into two groups: main criteria and additional criteria. The main criteria are used to resolve conflicts between path requests for two different types of train services (e.g. international passenger and highfrequency passenger trains). The analysis of the used criteria based on the type of service has led to the conclusion

\footnotetext{
${ }^{8}$ It does not refer to high-speed railways.
}

that all countries give priority to the services of passenger transport, which is quite diversified in most EU member states. Half of the IMs (12 out of 24 countries) give absolute priority to the passenger services of public interest (all trains in the PSO regime). In 8 other countries of the 24 analysed, high-frequency passenger trains are given absolute priority over other types of transport. In this group of the countries, high-frequency passenger trains also operate in the PSO regime (CER 2017), so that this criterion generally dominates other criteria. Immediately after these services, the service to which most of the IMs give priority includes fast international and domestic passenger trains (15 out of 24 countries). The criterion under which priority is given to a train service based on a framework agreement ${ }^{9}$ can also be included in the main criteria. In the event of a conflict, some IMs (10 out of 24) give priority to the services operated by TOCs with framework agreements ${ }^{10}$. In some EU member states, priority is given to a

\footnotetext{
${ }^{9}$ Framework agreements are concluded between the IM and TOCs with long-term investments in rolling stock (EC 2016). Under a framework agreement, the IM assumes the obligation to allocate to a TOC a certain number of paths on a specific part of the network, which it will be able to use over a period of time exceeding one working timetable period.

${ }^{10}$ Some countries set the limit for the percentage share of the paths for which a single TOC is granted priority in the total
} 
Table 1. Systematization of priority criteria applied for capacity allocation on congested infrastructure in EU member states ${ }^{*}$

\begin{tabular}{|c|c|}
\hline Criteria & Countries applying the listed criterion \\
\hline \multicolumn{2}{|r|}{ Main criteria } \\
\hline PSO train service & $\begin{array}{l}\text { Croatia, Czech Republic, Denmark, Greece, Hungary, Luxembourg, Poland, } \\
\text { Portugal, Romania, Slovakia, Slovenia, Spain (12 countries) }\end{array}$ \\
\hline High-frequency passenger train service & Austria, Belgium, Finland, France, Germany, Italy, Nederland, Switzerland (8) \\
\hline $\begin{array}{l}\text { Fast, international and domestic passenger } \\
\text { trains }\end{array}$ & $\begin{array}{l}\text { Austria, Belgium, Bulgaria, Czech Republic, Estonia, Finland, Germany, } \\
\text { Hungary, Italy, Luxembourg, Nederland, Norway, Poland, Slovakia, Slovenia (15) }\end{array}$ \\
\hline $\begin{array}{l}\text { Other passenger trains (low-frequency, regional } \\
\text { and slow passenger train types) }\end{array}$ & Belgium, Bulgaria, Finland, Greece, Hungary, Norway, Romania, Spain (8) \\
\hline Train service based on a framework agreement & $\begin{array}{l}\text { Austria, Czech Republic, France, Germany, Hungary, Italy, Norway, Slovenia, } \\
\text { Spain, Switzerland (10) }\end{array}$ \\
\hline Combined freight train service & Croatia, Czech Republic (2) \\
\hline International or fast freight train service & Bulgaria, Czech Republic, Finland, Germany, Hungary, Nederland, Norway (6) \\
\hline \multicolumn{2}{|r|}{ Additional criteria } \\
\hline \multicolumn{2}{|l|}{ Additional standard criteria } \\
\hline $\begin{array}{l}\text { Train service that runs on a longer route or with } \\
\text { more train-kilometres }\end{array}$ & Bulgaria, Croatia, Czech Republic, Finland, France, Hungary, Italy, Portugal (8) \\
\hline $\begin{array}{l}\text { Train service operating more days during the } \\
\text { year }\end{array}$ & $\begin{array}{l}\text { Bulgaria, Croatia, Czech Republic (primary criterion), France, Hungary, Italy, } \\
\text { Spain (7) }\end{array}$ \\
\hline $\begin{array}{l}\text { Train service with interval timetable or higher } \\
\text { frequency per day or week }\end{array}$ & Austria, Czech Republic, Finland, Hungary, Italy, Switzerland (6) \\
\hline \multicolumn{2}{|l|}{ Additional specific criteria } \\
\hline $\begin{array}{l}\text { Train service that generates higher total income } \\
\text { from access charges for IM }\end{array}$ & Belgium, Germany, Switzerland (primary criterion) (3) \\
\hline Earlier submitted a request for a TP & Bulgaria, Hungary, Slovenia (3) \\
\hline $\begin{array}{l}\text { Service that better utilizes infrastructure } \\
\text { capacity }\end{array}$ & Slovenia, Spain (2) \\
\hline Socio-economic analysis & Norway, Sweden (primary method for priority assessment) (2) \\
\hline $\begin{array}{l}\text { TOC with better utilization of TPs in the } \\
\text { previous timetable }\end{array}$ & Croatia, Germany, Poland (3) \\
\hline Train service with longer travel time & Croatia, Hungary (2) \\
\hline $\begin{array}{l}\text { Highest bidder procedure (sealed-bid first-price } \\
\text { auction) }\end{array}$ & Germany, Poland, Slovenia, Switzerland (4) \\
\hline
\end{tabular}

Notes: ${ }^{*}$ the order of applied priority criteria, which is stated in network statements of some IMs may vary;

${ }^{* *}$ fast, international and domestic passenger trains have the highest train rank in Belgium, Bulgaria, Estonia, Italy and Poland.

combined freight train service and international and fast freight trains over some types of passenger trains.

If there is a conflict between path requests submitted for the same type of service categorized according to the main criteria, the IM uses additional criteria. It can be noticed that IMs are governed by a wide spectrum of additional criteria. Based on how frequently they are published in national network statements, additional criteria can be further classified as additional standard (more frequent) and additional specific (less frequent) criteria.

The additional standard criteria, used by many IMs, include TPs of long-distance trains or giving priority to services provided most of the year or services with a higher daily or weekly frequency. IMs often give priority to a train service operated on a longer route over that operated on a shorter route ( 8 out of 24 ). In addition to this, a

number of paths on a given railway. certain number of IMs give priority to services provided over longer periods of time covered by the timetable over services provided over shorter periods of time (7 out 24). The criterion under which priority is given to services with a higher daily or weekly frequency is similar to this criterion (6 out 24 ). Some countries combine the criterion of route length and operation frequency by giving priority to service likely to achieve greater mileage in a given year (the criterion is used to give priority to requests in rail freight corridors).

Network statements also include the criteria, which can be described as additional specific criteria due to their features and the fact that they are used by a few countries only. In terms of costs, one of the most interesting criteria is giving priority to a path request that will bring greater income to the IM from infrastructure access charges (Belgium, Germany and Switzerland). On the other hand, in some cases additional specific criteria not directly linked to a specific path request but depending on the charac- 
teristics and output of the applicant TOC are used. One such example is the criterion under which the IM values more the request submitted by a TOC with a higher railway infrastructure utilization rate in the previous timetable (Croatia, Germany and Poland). Very rarely, a cost-benefit analysis, including several factors, is used to decide, which request should be given priority (Norway and Sweden). A few countries have the highest bidder procedure in place, if conflicting path requests cannot be dealt with in any other way. Germany, Poland, Slovenia and Switzerland use sealedbid first-price auctions, in which TOCs submit sealed bids they are ready to pay for the paths they request. The auction winner is the TOC with a higher bid paid to the IM.

Based on the overview and systematization of the published priority criteria, it is evident that most of the criteria rely on the type of service. Moreover, the typeof-service criteria play a decisive role in priority giving in almost every EU member state. The high number of such criteria leads to the conclusion that they are in fact primarily used to "avoid" the value-of-service criteria. This means that their usage maintains the "status quo" of premarket relations, giving priority to services with higher social value rather than those with the market value. On the other hand, auctions are still more of an enforced solution, used to deal with a problem in situations when all other possibilities have been exhausted, than a path allocation mechanism one is committed to.

\subsection{Evidence of deficiencies with current practice}

Summing up the analysis of priority criteria used in TP allocation, we have identified three main problems:

- allocation inefficiency due to absolute priority being given to passenger transport services;

- current capacity allocation procedure is overregulated and as such insensitive to market requirements;

- lack of transparency in the design process of the draft timetable.

It is evident that the criteria are based on the historical assumption that freight transport services are much more flexible than passenger transport services. When designing the timetable i.e. allocating TPs, passenger trains are given priority over freight transport, regardless of how the TOCs' requests are valued. This means that priority criteria give importance to the services expected to have a higher social value, often at the expense of the services with a higher market value, which leads to inefficient allocation ${ }^{11}$. The freight operators are oriented to maximizing the profit and therefore these operators are often willing to pay more for a path ${ }^{12}$, especially TOCs that provide transport of containers, cars, coal, perishable goods etc. (Matthews et al. 2009; ECMP 2005).

\footnotetext{
${ }^{11}$ Allocation is efficient if the chosen allocation mechanism gives paths to the TOCs that value them most (Perennes 2014);

12 In late 2011, the freight operators using the Rhine-Alpine corridor (between Rotterdam and Genoa), which is Europe's busiest freight route, urged the corridor's IM to give priority to freight trains and TPs should be constructed based on market needs (EEIG Corridor Rhine-Alpine EWIV 2011).
}

The above mentioned especially refers to cases of congested infrastructure. In a situation when the competition of railway services is introduced, one can rightly ask why priority is still being determined based on the non-market criteria. Specifically, this refers to socially important transport services on congested infrastructure sections, where the value of capacity usage is high. Moreover, the majority of passenger transport services, which are under PSO umbrella, are provided by incumbents. Furthermore, incumbents have the right to provide public transport services, usually directly awarded by state or regional authority (EC 2014). This makes it possible for incumbents to preserve their inherited right to a large number of paths. At the same time, freight operators are placed in a subordinate position due to the type of service they provide, because it is not treated equally with the passenger transport service.

Another problem is the insensitivity of the administrative mechanism to changes in the rail market. Freight transport by railway has been for decades exposed to the fierce competition of road haulage and, consequently, freight operators have to adapt more quickly to market changes and new trends. However, the railway system has remained insensible to adapting transport services to the market and more focused on addressing technical problems. On the other hand, due to its monopolistic position, the IM is not too keen on changing priorities frequently to accommodate market requirements, which sends a message about the system's inflexibility to respond to market requirements as soon as possible.

Finally, the third problem concerns the very process of draft train timetable design. Despite the vertical separation of incumbents by activity, the IM still prepares a draft timetable in the same traditional way using priority criteria from the monopoly era. As Nilsson (2015) noticed, today's process is extremely slow with almost three months passing between the submission of requests and the announcement of a draft timetable. Moreover, he argues that only one additional iteration is feasible before the final schedule is settled, as well as that the principles governing the final schedule are non-transparent. It can be concluded that, in this way, IMs ensure for themselves a certain degree of flexibility in draft timetable design, which is indeed in line with Directive 2012/34/EU (EC 2012) but introduces a certain amount of non-transparency into the whole process. This is important because, once a draft timetable is released, no major path adjustments should be expected. In other words, there is still a central entity proposing the timetable to TOCs, which in most cases can accept, reject or at best adjust it to a very limited extent. As a result, the current draft timetable design procedure largely predetermines the outcome of capacity allocation on congested infrastructure.

Based on all mentioned above, one can conclude that the current procedure for capacity allocation on congested infrastructure slows down the development of competition on the railway network. This, in particular, reflects on the liberalized rail freight market. On infrastructure sections with insufficient capacity for all TOCs, the current 
path allocation procedure does not give a satisfactory solution for the growing number of new TOCs, especially as regards the services with a higher market value. The problem is present in international freight transport (especially outside the rail freight corridors) and at access points to major railway nodes, faced with high and uncoordinated requests for paths for several different transport services.

\subsection{Summary}

TP allocation is one of the rail sector's activities that has failed to undergo appropriate changes after the opening up of the market. The traditional priority rules of TP allocation, based on the use of transport service-based priority criteria, are still existing despite the open access regime. The new TOCs in the market, which often specialize in specific types of transport, are willing to pay more for TPs. With the emergence of competition, the problem of TP allocation on congested infrastructure sections has become more complex.

The traditional priority rules of capacity allocation do not only slow down the competitiveness in the rail market, they also affect the competitiveness of railways in the transport market. By giving priority to services important to society, the current method of timetable design does not ensure efficient capacity allocation, especially of congested infrastructure. As a result, the train timetable does not reflect train operators' requests. Moreover, by keeping the same priority criteria, the IM cannot respond fast to new requests by freight transport operators and in particular new operators. For this reason, the TOCs' freight transport services continue to be inferior to the services provided by road haulage.

In order to support further development of the rail market, priority criteria based on the type of service should be replaced by the train service market value criterion. This means that a shift should be made from the centralized approach of path allocation to the decentralized one. Under the decentralized approach, TOCs would place bids in auctions in the event of conflicting requests for TPs on congested infrastructure. The use of market mechanisms and in particular auctions would ensure the TOCs' more active role in setting the price of TPs.

\section{The decentralized approach to TP allocation}

\subsection{Concept description}

The fully decentralized approach of TP allocation on railways allows TOCs to propose their timetables to the IM in the form of requests for TP bundles (Perennes 2014). Their proposals include requests for one or more paths they need in order to meet the end-user requirements. Within a single bundle, TPs can be independent or complementary, which is quite common in passenger transport. To create a path request, a train operator allocates the desired time of departure from the origin station and the desired time of arrival at the destination station to each requested path, with possible stops along the route. In this way, each train operator designs its own, ideal timetable based on a specific service pattern it has to provide to its end users. A train operator should determine valuation for each path or path bundle proposed in its request.

Unlike the centralized approach of capacity allocation, under which the transport service priority is the main path allocation criterion, the decentralized approach treats equally path requests from different services. In view of the creation of a single European rail area, which treats equally all TOCs, regardless of whether they are incumbents or newly emerged operators in the market and the type of service they provide, the main path allocation criterion that would stimulate the efficient use of infrastructure is the TOCs' willingness to pay the path price. The path price would be determined by the TOCs' bids during the auction procedure. The decentralized capacity allocation is therefore bound to the auction mechanism.

\subsection{Literature review}

The increasingly widespread use of auctions in other public sectors and the crawling pace of opening up of Europe's rail market have prompted researchers to solve the problem of uncoordinated conflict demand for TPs using the decentralized approach to capacity allocation on railways. Initial reactions to the idea of using auctions to allocate railway infrastructure capacity were highly sceptical. The first major research dealing with the issue on railways was the paper by Brewer and Plott (1996), one of its main objectives being to examine the arguments of the proponents of the thesis that it is not at all possible to use decentralized TP allocation due to the technical specificities of rail transport. The authors discussed the controversies of the decentralized approach such as adjusting other participants' timetables to the paths already allocated to the auction winner, high transaction costs to TOCs and network fragmentation aimed at maximizing the IM's income. Despite that, one of the paper's key conclusions is that, in a limited experimental testbed, decentralized path allocation can solve specific technical and economic issues embedded in the railway infrastructure capacity allocation problem. Moreover, according to Brewer and Plott (1996), the use of auctions is not only possible, but it also yields better results in terms of TP allocation efficiency.

This paper was followed by papers dealing with the potential use of auctions and its impact on TOCs and society $^{13}$. Nilsson (2002) suggests at one point in his paper that using the auction mechanism is possible to strike the balance between conflicting demands in situations with insufficient infrastructure capacity. The auction is then an

\footnotetext{
${ }^{13}$ Outside Europe, the rail sector is still vertically integrated so that decentralized TP allocation cannot be applied to it. However, in the US rail freight operators having their own railway infrastructure have to enable other TOCs to use it at fair prices. Due to the above mentioned, the US approach to the TP allocation problem is different than the European approach; the problem was studied by a number of authors including (Levy et al. 2015; Peña-Alcaraz 2015; Talebian et al. 2018).
} 
inherent part of a scheduling process that generates two outputs: a timetable and a set of (congestion) charges. In the same paper, he studied the problem of incentives for TOCs to encourage them to place bids that reveal their true path valuation (value-of-access function). Using the value-of-access function, the author demonstrated how a TP value to a TOC depended on the allocated departure and arrival times of trains, which Bablinski (2016) later used in his work. Nilsson (2002) also studied the problem of maintaining a higher level of social welfare, establishing that it was difficult to foresee the financial implications of an auctioning procedure and whether it would make a significant difference in reducing the financial deficit from a welfare-enhancing policy. For that reason, he suggested that some non-profitable transport services be granted privileged status (positive discrimination), using US auctions of radio frequency bands for local radio stations as a template. Later on, Jansson and Lang (2013) tackled the problem of the introduction of auctions for TP allocation in Sweden, claiming that auctions ignored the welfare aspect. According to them, auctions may work to a limited extent for Sweden's regional public transport authorities in charge of commuter train services, because they claim that they base their decisions purely on social welfare.

Some papers also focused on the issue of whether it was better to use TP auctions for on-track competition or for off-track competition. In her paper, Affuso (2003) described the features of the two conflicting auction concepts. The first concept is used when competing for franchises for passenger transport services in Great Britain (competition for the market), while the other concept is based on the allocation of individual TPs to TOCs (direct or competition in the market). The paper listed the advantages of using auctions to sell individual TPs over competitive tendering for the sale of franchises, because, in the first case, auctions stimulate more efficient use of infrastructure. Although combined auctions were considered to be the logical option, Affuso (2003) listed the downsides of this type of auctions in TP allocation, such as potential high transaction costs of TOCs and the fact that the existing regulatory mechanisms are not sufficient to prevent discrimination. To reduce transaction costs, Perennes (2014) later suggested in her paper that the auction designer (IM) should decide which auction mechanisms will be used and for which combinations bids should be allowed, offering TOCs specially designed TP bundles for specific services and market segments. However, the author herself predicted that, even though this would result in lower transaction costs to TOCs, it would mean a discreet shift from the concept of on-track competition to the concept of off-track competition, which is a conclusion quite similar to that drawn by Affuso (2003).

Gibson (2003) and Talebian et al. (2018) also studied potential TP allocation mechanisms and their features. Apart from the administrative mechanism, the authors TP allocation mechanisms, namely the value-based mechanism and focused on the market-based mechanism, which, unlike the administrative mechanism, encourage train op- erators to use infrastructure efficiently. Quinet (2003), too, researched the value-based mechanism and the effects of introducing congestion charges. He argues that the main purpose of the congestion charges in practice is to cover a part of the IM's costs while reducing higher demand for TPs has secondary importance. Quinet (2003) concludes that IMs can neither accurately determine the costs arising from the lack of infrastructure nor properly allocate them to the TOCs in a non-discriminatory manner. One of the factors preventing the IM from determining the costs related to the lack of infrastructure is the lack of precise information about the demand for and value of transport services after the opening up of the rail market because TOCs now keep this information secret (Klabes 2010). Due to the fact that it is not familiar with the demand curve, it is hard for the IM to set the price at which it can sell the usage of the entire available capacity, which leads to insufficient capacity utilization or the reduction of higher demand using additional criteria (Stern, Turvey 2003).

The market-based mechanisms apply mostly to vertically separated systems, seeking to elicit prices that train operators are willing to pay for their desired TPs, at the same time taking into account congestion impact (Talebian et al. 2018). One prominent form of market-based mechanisms is an auction ${ }^{14}$. Summing up the effects of introducing auctions for the purpose of TP allocation, Nilsson (2002) concludes that this mechanism simultaneously solves two problems that are today addressed separately, namely the problem of TP allocation and the problem of setting congestion charges, as well as that TOCs themselves play the main role in setting the price. As for the market-based mechanism, Gibson (2003) concludes that the rail sector's complexity hinders and yet does not pre-

\footnotetext{
${ }^{14}$ According to the economic literature, there are three ways to allocate a scarce resource: administratively, in a lottery or in auctions (Milgrom 2004). The administrative mechanism cannot achieve efficient allocation and often encourages corruption. The lottery provides equitable treatment of participants because it randomly assigns the objects but cannot achieve efficient allocation. Moreover, it produces secondary reselling market for objects since the lottery winner has an incentive to re-sell the at a higher price to a person who is willing to pay more, attracting many participants and delaying the use of allocated rights, as already happened with the spectrum license lottery in the US (Osborne 2004). Therefore, even if the bargaining under incomplete information results in ex-post efficient allocation (which does not need be the case), the lottery does not provide more equitable treatment than auction and it only reduces the revenue for the IM at the expense of the lottery winner. Moreover, the lottery can attract speculators who are not willing to use the rights, and only seek to obtain the profit from resale. Auctions can achieve efficient allocation and yield high revenue for seller. In some auction mechanisms (hybrid auctions) the bidder with the highest willingness to pay does not need to win the auction, and this auction provides more equitable treatment of bidders at the cost of a slight reduction of efficiency. Compared to the administrative mechanism, auctions provide ex-ante non-discriminatory treatment of all participants in terms of equity.
} 
vent the use of auctions of TPs on railways. He believes that one of the biggest problems in using auctions is the resistance shown by incumbents, for which this would mean losing their inherited right to TPs (so-called grandfather rights), dating back to the era of the monopolistic rail market. Perennes (2014) also analysed the reasons for the big gap between the theoretical advantages of auctions and their practical application in the rail sector from the economic aspect. She compared the centralized approach of TP allocation to the decentralized in order to determine which one is the most efficient, according to two dimensions - allocation efficiency and transaction costs. One of the conclusions she makes in her paper is that it is extremely hard to allocate capacity on a rail network if only one combined auction is used, especially when large networks are involved. It is not just that the transport volume is unequally distributed across any IM's network, but many network sections are very underutilized. It is therefore not rational to use a single combinatorial auction to design the entire timetable. Another reason why a single combined auction cannot be used for an entire network is that the different types of services dominate different parts of a network. Based on that, Perennes (2014) suggests that auctions be used only on specific parts of a network faced with high demand, which is indeed the main point of using auctions, i.e. they should be only used if there is sufficient competition for the scarce resource.

The literature review shows that the authors primarily focused on the advantages of auctions over the current administrative mechanism. However, there was no in-depth analysis of the capacity allocation procedure based on the decentralized approach, which would make possible the use of auctions. This does not only refer to the functionality of the approach and procedures but also to defining the roles of the participants in the allocation procedure. The new capacity allocation procedure would have to meet specific requirements in order to bridge the technological gap between the use of auctions for TP allocation and timetable design. In other words, the resolution of specific controversies related to the use of decentralized TP allocation and auctions can lead to an algorithm that will enable their practical application on railways.

\section{Proposed new TP allocation algorithm, based on the fully decentralized approach}

\subsection{Requirements the algorithm has to meet}

The discussion about the centralized approach to TP allocation shows that the rail sector has to change its current approach to path allocation. On the other hand, the aim of the discussion about the disadvantages of decentralized $\mathrm{TP}$ allocation was to identify the shortcomings, challenges and potential problems that participants can face in the allocation process.

Taking into account the above mentioned, a new TP allocation procedure, which would further support open access competition, can be developed. This means that it is possible to design and propose a new TP allocation algorithm, with its steps and phases, as well as the defined roles of the participants in it. In addition to its being market-based, the algorithm would be in line with the ideas and goals of systemic Directive 91/440/EEC (EC 1991) on boosting competition among train operators and preventing discrimination against some of them. Consequently, the new algorithm has to meet several requirements:

- the algorithm must treat all path requests equally (as well as all types of services and, consequently, TOCs), which primarily excludes the use of the transport service-based priority criteria;

- in view of the fact that the algorithm is marked-based (which means that the train operators that value their TPs most, for them are given priority in TP allocation), the algorithm has to include some kind of TP auction;

- the algorithm must be capable of solving conflicts between path requests;

- auction non-winner train operators should have a chance to adjust their initial requests and compete again in another auction;

- the IM should be willing to use all available capacity if need be.

The first requirement indicates that paths should no longer be allocated and drawn using the order of the predefined train rank (primarily based on the type of service) or any of the already mentioned additional criteria; path allocation should instead depend on bids made by train operators in their path requests. If there is a conflict between two or more path requests, the algorithm should enable train operators to compete for paths in an auction on equal terms (second requirement). The third requirement describes the way of solving conflicts. The IM should not necessarily initiate an auction for the smallest conflict between path requests. Instead, its role is (as always) to identify and assess the scale of congestion and to decide based on that whether the conflict can be solved in negotiations with the train operators concerned within a reasonable period of time.

The fourth requirement is about adjusting the path requests of other train operators to the auction winner. In order to enable these train operators to adjust their requests and submit new ones, the decentralized TP allocation algorithm should be iterative, i.e. certain phases should be repeated through iterations as long as the demand for capacity (by train operators) does not meet the supply of available capacity (by the IM). After each iteration, the IM should reassess the available capacity and decide whether there is enough capacity to allocate and, if there is, train operators should get a chance to adjust their requests with the already allocated paths, which is the fifth requirement.

\subsection{Phases of the TP allocation algorithm}

In the initial phase, the IM receives path requests from the 
interested train operators. On the other hand, in the final phase, the IM announces the working timetable, made up of conflict-free TPs. Between the initial and final phases, four other potential phases can be defined, but, depending on the allocation circumstances, not all phases have to be used. Figure 2 shows the suggested structure and links between the different phases.

The initial phase in which path requests are gathered would be followed by the phase of potential conflict identification. If there is a conflict between path requests, the procedure will enter the coordination phase. If no solution is found in this phase, the auction phase will follow. The auction is followed by the consolidation of the used capacity of the IM and the capacity requested by train operators not winning the auction. Depending on whether there is the available capacity to allocate and whether there are new or altered path requests, the algorithm can go onestep back to the auction phase. If not, or if there is no conflict between a new or altered request for paths, the algorithm will enter its final phase. The final phase (working timetable) can be reached from the phase of potential conflict identification (if no conflicts are identified), the coordination phase (if all conflicts are successfully resolved), or the consolidation phase (if there is no available capacity for allocation or new or altered path requests).

In addition, depending on the scale of congestion, the algorithm offers a two-step problem approach: using coordination as described in Directive 2012/34/EU (EC 2012), if the estimated congestion scale is small, and using auctions, if the estimated congestion scale is such that coordi-

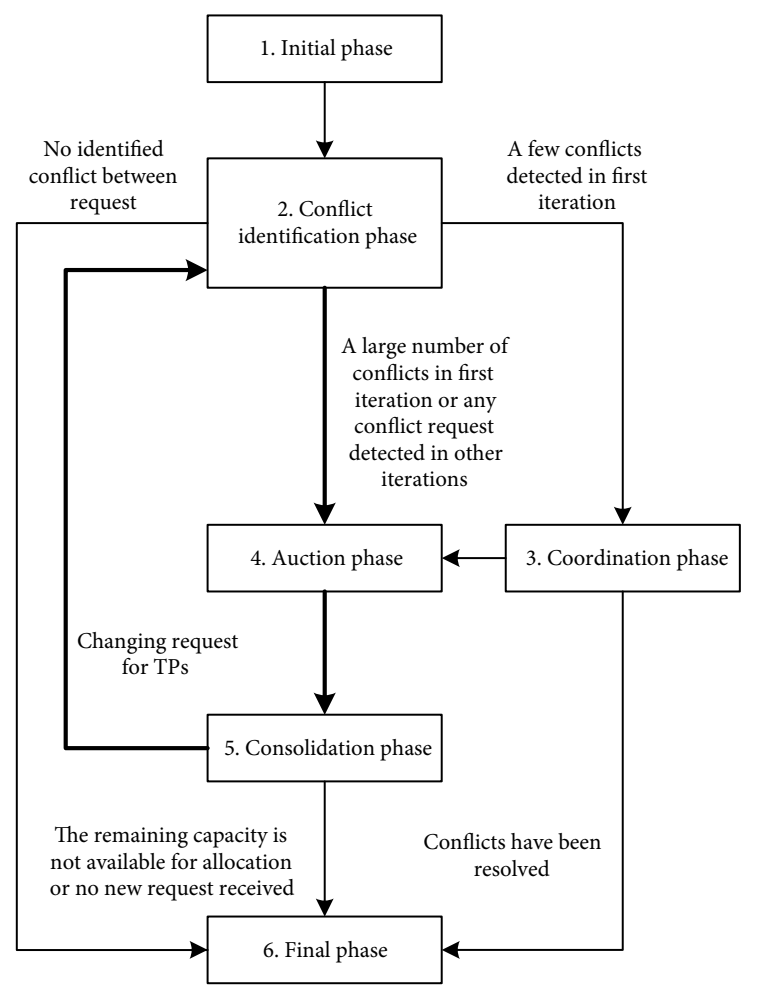

Figure 2. Main phases and their correlation in the algorithm for TP allocation nation cannot result in a solution within the time limit set for negotiations. Moreover, it would be possible to move to the auction phase directly from the phase of potential conflict identification, if the IM could prove that the congestion scale is large.

\subsection{Defining the participants' roles and the algorithm}

If the proposed algorithm is analysed together with the allocated roles of the participants in capacity allocation, the phases of the algorithm shown in Figure 3 will be somewhat more complex. For this reason, the complete algorithm of fully decentralized TP allocation consists of a sequence of numbered steps:

- Step 1. The capacity allocation procedure starts with the train operators' submission of requests for one or more paths to the IM. The requests include the desired departure and arrival times of trains as well as the maximum deviation (tolerance) from the ideal departure times and trip duration. A train operator's path request must not include any paths that conflict with each other inside a bundle;

- Step 2. The IM draws the requested paths in the timetable graph and checks if there are any conflicts between requests submitted by different train operators. The IM can use the tolerances previously submitted by train operators to solve potential smaller conflicts, without consulting the train operators concerned. If there are no conflicts, paths will be drawn as requested and train operators will pay infrastructure access charges for TPs according to the formula listed in the relevant network statement. The IM will then release the final version of the working timetable and at this point the algorithm ends;

- Step 3. If there are conflicts between two or more path requests, the IM will try to adjust the requested paths in negotiations with train operators in the coordination phase. If the IM manages to solve completely all conflicts between path requests together with train operators, it will allocate paths to train operators, which will pay the access charges as described in Step 2. After that, the IM will release the final version of the working timetable and at this point, the algorithm ends. However, if this step does not result in a conflict-free timetable graph, the IM will declare congestion on a given part of the infrastructure and organize an auction;

- Step 4. At the auction in which the train operators involved in a conflict place bids, the IM announces the winner, which pays the price set as per the rules of the auction used in the algorithm;

- Step 5. Once one or more paths from the first iteration are drawn in the timetable, the IM presents the new version of the timetable to train operators. One section of the available railway capacity is used in each iteration. Based on the technical parameters of the timetable (e.g. infrastructure capacity utilization 


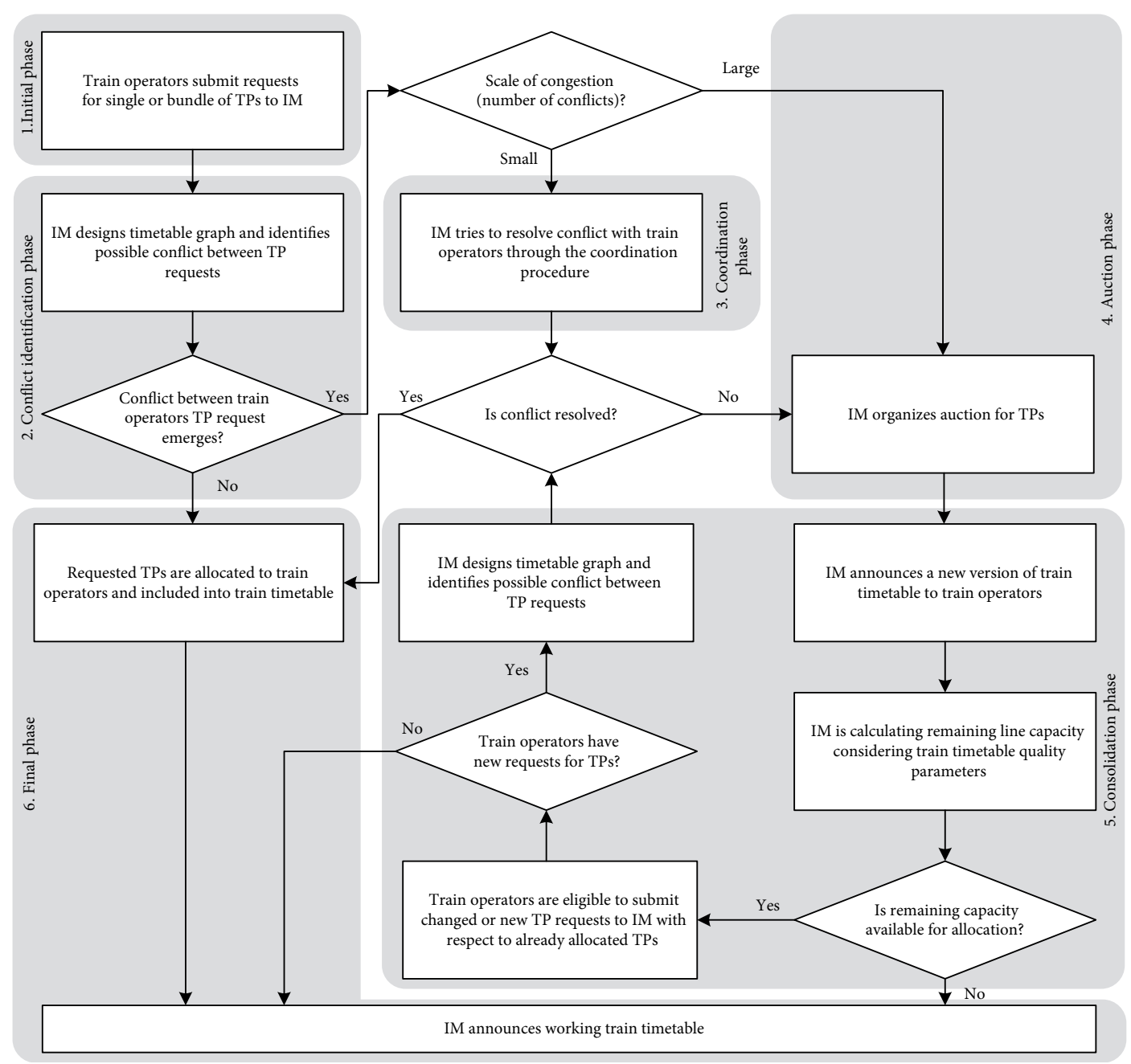

Figure 3. Proposed full algorithm for TP allocation based on the decentralized approach

and train timetable robustness), the IM has to assess after which iteration capacity allocation should end. If there is no capacity sufficient for allocation, the IM will release the final version of the working timetable and at this point, the algorithm ends;

- Step 6. If there is remaining capacity available to allocate, the IM will inform the interested train operators that they should submit new path requests, which now have to be in line with the paths drawn in the first iteration. The paths sold in previous iterations are fixed and have priority over the paths allocated in subsequent iterations, which have to be adjusted to them. Train operators will be given a deadline by which they have to submit altered or new path requests and the new iteration will proceed in the same way as the previous one. If the IM does not receive any altered or new path requests, the draft timetable last released will be declared as working timetable and at this point, the algorithm ends. However, if the IM receives new or altered requests, it will start processing them as described in Step 2. If it identifies any conflicts between them, it will organize an auction i.e. a new capacity allocation iteration, as described in Step 4.
The proposed TP allocation algorithm is the result of synthesis of the general features of the decentralized approach, on the one hand, and the features of a TP as an allocation resource, on the other.

At the same time, the new algorithm is designed so as to meet the above criteria, with the clearly defined roles of participants and the sequence of steps. In this way, when analysing the way in which the algorithm proceeds, one can say that the planned roles of specific participants have been defined and regulated so as to enable the procedure to run sequentially. This ensures a higher level of transparency in infrastructure capacity allocation, making it easier to follow the timetable planning process, as well as the process of decision-making and providing the relevant rationale (especially if path requests are rejected). Moreover, the clear definition and use of procedures for the resolution of the path allocation problem make it possible to respond speedily to the set requests and, ultimately, to lower the IM's timetable design costs.

Compared to the current/centralized approach, the new algorithm based on the decentralized approach makes it easier for the IM to design and propose a draft timetable since it is easier to suggest solutions and make decisions. The transition from priority criteria based on the type of 
transport service to priority criteria based on the market value of service enables train operators to submit their requests for path bundles freely and to bid for their requests in auctions. As a result, train operators valuing their TPs most get them first with minimum uncertainty and extra transaction costs. On the other hand, it reduces the room for unprofitable services, increasing the value of the timetable and the efficiency of railway infrastructure capacity usage, as illustrated in Figure 4.

The proposed new algorithm is based on the assumption that an absolutely empty timetable graph is used to

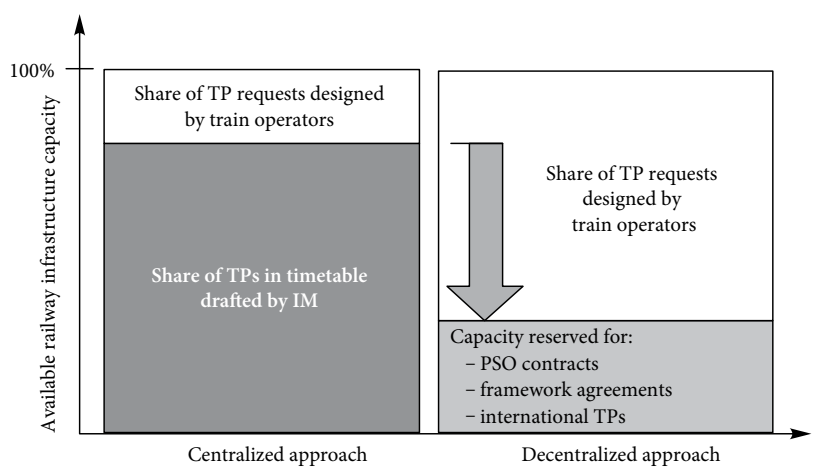

Figure 4. Direct comparison of two approaches of TP allocation to the corresponding degree of train operators' freedom to design and request TPs

draw TPs and that the maximum infrastructure capacity is available for allocation to the interested train operators (fully decentralized TP allocation). However, the same as there is no fully open market in practice, there can be no absolutely empty timetable graph, because the IM has to reserve some capacity for the purposes of railway infrastructure maintenance (closing and repair of tracks and equipment) and for the paths for the public transport services and train services operated under framework agreements, as well as the paths agreed to be used in international transport and ad-hoc path requests. This paper is not concerned with the optimum share of these paths in the timetable, but it can be assumed that the bigger the volume of these services in the timetable, the closer the allocation procedure gets to the centralized approach and vice versa. The application of the new algorithm could result in a reduced volume of unprofitable transport services, inherited from the pre-restructuring period and covered today by national programs for PSO.

\section{Conclusions}

Today's capacity allocation mechanism used on Europe's railway infrastructure makes it impossible for the rail market to develop despite the fact that this is the key guideline of the EU's transport policy. The paper proposes a new railway infrastructure capacity allocation algorithm that enables the use of auctions in capacity allocation. Despite the fact that the use of auctions would be limited to congested infrastructure sections only, it would present a great challenge to the rail sector. The use of auctions for TP al- location is characterized by the controversies reflected in specific technical and economic issues such as the train operators' high transaction costs, the absence of social welfare aspect, the complementarity of rail transport services, etc. They are the result of the lack of compatibility between the auction mechanism requirements on the one hand and the specific features of rail transport, on the other. The gap can be bridged by a well-designed procedure, which will take into account the specific requirements and conditions resulting from the controversies related to the use of decentralized TP allocation on railways.

Without prejudging the type of auction to be used for TPs, we have designed an algorithm based on decentralized path allocation. The proposed TP allocation algorithm has been formulated in such a way as to enable TP allocation iteratively. The primary goal of the proposed algorithm is to ensure a higher level of allocation efficiency. The application of the proposed algorithm has the potential to increase the value of the timetable and reduce the volume of unprofitable services. On the other hand, the clearly defined procedures, given in the form of the new algorithm, have made possible the interaction between all parties involved in timetable design, so that the market-based criterion of TP allocation has primary importance. Furthermore, the application of the proposed algorithm represents a multidimensional approach, which makes it possible to establish relations between applicants, timetable design and the method of conflict resolution on market principles.

In addition, the advantage of the proposed algorithm lies in the fact that the use of auctions is adapted to the capacity allocation circumstances. Moreover, the algorithm is iterative, so that train operators can adjust their requests in subsequent iterations as well as get signals about how much their competitors are willing to pay for TPs. The planned roles of specific participants are defined so as to enable the capacity allocation procedure to be sequential. This ensures a higher level of transparency in infrastructure capacity allocation, making it easier to follow the timetable planning process, especially if it comes to the decision of altering or rejecting a TP request. Moreover, the proposed algorithm will be more equitable and will offer an equal chance to small train operators. This will increase competitiveness on rail networks, automatically boosting the competitiveness of train operators in the transport market in general.

Judging by the current pace of rail market development, as well as the obstacles hampering greater competitiveness among TOCs, there is a need to "reset" the railway infrastructure capacity allocation procedure. As we are on the threshold of full liberalization of Europe's rail freight market (2018) and passenger (2019) transport services $^{15}$, a new TP allocation mechanism will be required. In proposing a new algorithm, the paper suggests an approach, which would help decision-makers solve the im-

\footnotetext{
$\overline{15}$ According to the Fourth Railway Package of 2016 (EC 2019).
} 
portant problem of transport policy problems in the EU rail sector.

\section{Acknowledgements}

This research was conducted under the auspices of Project TRA36022 (2011-2019) "Management of critical infrastructure for sustainable development of postal, telecommunication and railway sector in the Republic of Serbia", funded by the Ministry of Education, Science and Technological Development of the Republic of Serbia.

\section{Author contributions}

The authors of this paper (Nikola Stojadinović, Branislav Bošković and Mirjana Bugarinović) were responsible for conducting the research (including all parts of the paper, e.g. literature review, analysis, and interpretation of findings).

\section{Disclosure statement}

The authors of this paper did not receive any grant nor were sponsored by any company. Therefore, the authors declare that they are free from bias or personal gain, which could lead to a financial conflict of interest with any other parties.

\section{References}

Affuso, L. 2003. Auctions of rail capacity?, Utilities Policy 11(1): 43-46. https://doi.org/10.1016/S0957-1787(02)00057-7

Bablinski, K. 2016. A game-based analysis of freight paths allocation with a case study on Great Britain Brighton main line, Transportation Research Procedia 13: 196-208. https://doi.org/10.1016/j.trpro.2016.05.020

Bassanini, A.; La Bella, A.; Nastasi, A. 2002. Allocation of railroad capacity under competition: a game theoretic approach to track time pricing, Applied Optimization 63: 1-17. https://doi.org/10.1007/978-1-4757-6871-8_1

Bergantino, A. S.; Capozza, C.; Capurso, M. 2015. The impact of open access on intra- and inter-modal rail competition. A national level analysis in Italy, Transport Policy 39: 77-86. https://doi.org/10.1016/j.tranpol.2015.01.008

Beria, P.; Quinet, E.; De Rus, G.; Schulz, C. 2012. A comparison of rail liberalisation levels across four European countries, $R e$ search in Transportation Economics 36(1): 110-120.

https://doi.org/10.1016/j.retrec.2012.03.014

Borndörfer, R.; Grötschel, M.; Lukac, S.; Mitusch, K.; Schlechte, T.; Schultz, S.; Tanner, A. 2006. An auctioning approach to railway slot allocation, Competition and Regulation in Network Industries 1(2): 163-196. https://doi.org/10.1177/178359170600100204

Brewer, P. J.; Plott, C. R. 1996. A binary conflict ascending price (BICAP) mechanism for the decentralized allocation of the right to use railroad tracks, International Journal of Industrial Organization 14(6): 857-886.

https://doi.org/10.1016/0167-7187(96)01014-4

Burdett, R. L.; Kozan, E. 2010. A disjunctive graph model and framework for constructing new train schedules, European
Journal of Operational Research 200(1): 85-98.

https://doi.org/10.1016/j.ejor.2008.12.005

Caprara, A.; Kroon, L.; Monaci, M.; Peeters, M.; Toth, P. 2007. Passenger railway optimization, Handbooks in Operations Research and Management Science 14: 129-187. https://doi.org/10.1016/S0927-0507(06)14003-7

CER. 2017. Public Service Rail Transport in the European Union: an Overview. Community of European Railway and Infrastructure Companies (CER), Brussels, Belgium. 144 p. Available from Internet: http://www.cer.be/publications/ latest-publications/public-service-rail-transport-europeanunion-overview

EC. 2019. Fourth Railway Package of 2016. Available from Internet: https://ec.europa.eu/transport/modes/rail/packages/2013_en

EC. 2016. Commission Implementing Regulation (EU) 2016/545 of 7 April 2016 on Procedures and Criteria Concerning Framework Agreements for the Allocation of Rail Infrastructure Capacity. Available from Internet: http://data.europa.eu/eli/reg_impl/2016/545/oj

EC. 2014. Report from the Commission to the Council and the European Parliament: Fourth Report on Monitoring Development of the Rail Market. Available from Internet: https://ec.europa. eu/transport/modes/rail/market/market_monitoring_en

EC. 2012. Directive 2012/34/EU of the European Parliament and of the Council of 21 November 2012 Establishing a Single European Railway Area. Available from Internet: http://data.europa.eu/eli/dir/2012/34/oj

EC. 2001. Directive 2001/14/EC of the European Parliament and of the Council of 26 February 2001 on the Allocation of Railway Infrastructure Capacity and the Levying of Charges for the Use of Railway Infrastructure and Safety Certification. Available from Internet: http://data.europa.eu/eli/dir/2001/14/oj

EC. 1991. Council Directive 91/440/EEC of 29 July 1991 on the Development of the Community's Railways. Available from Internet: http://data.europa.eu/eli/dir/1991/440/oj

ECMP. 2005. Railway Reform and Charges for the Use of Infrastructure. European Conference of Ministers of Transport (ECMT); Organisation for Economic Cooperation and Development (OECD) Paris, France: OECD Publishing. (OECD), Paris, France. 134 p. https://doi.org/10.1787/9789282103524-en EEIG Corridor Rhine-Alpine EWIV. 2011. Rail Freight Companies Present their Requirements for the Corridor RotterdamGenoa. Available from Internet: https://www.corridor-rhinealpine.eu/news-detail/rail-freight-companies-present-theirrequirements-for-the-corridor-rotterdam-genoa.html

Eurostat. 2018. Statistical pocketbook 2018: EU Transport in Figures. 164 p. Available from Internet: https://publications.europa.eu/en/publication-detail/-/publication/52f721ed-c6b811e8-9424-01aa75ed71a1

Gibson, S. 2003. Allocation of capacity in the rail industry, Utilities Policy 11(1): 39-42. https://doi.org/10.1016/S0957-1787(02)00055-3

Jansson, K.; Lang, H. 2013. Rail infrastructure charging EU-directive, Swedish concerns and theory, Research in Transportation Economics 39(1): 285-293.

https://doi.org/10.1016/j.retrec.2012.06.026

Klabes, S. G. 2010. Algorithmic Railway Capacity Allocation in a Competitive European Railway Market. PhD Dissertation. RWTH Aachen University, Germany. 209 p. Available from Internet:

http://darwin.bth.rwth-aachen.de/opus/volltexte/2010/3134

Kozan, E.; Burdett, R. 2005. A railway capacity determination model and rail access charging methodologies, Transportation 
Planning and Technology 28(1): 27-45. https://doi.org/10.1080/0308106052000340378

Levy, S.; Peña-Alcaraz, M.; Prodan, A.; Sussman, J. M. 2015. Analyzing financial relationship between railway industry players in shared railway systems: train operator's perspective, Transportation Research Record: Journal of the Transportation Research Board 2475: 27-36. https://doi.org/10.3141/2475-04

Luan, X.; Corman, F.; Meng, L. 2017. Non-discriminatory train dispatching in a rail transport market with multiple competing and collaborative train operating companies, Transportation Research Part C: Emerging Technologies 80: 148-174. https://doi.org/10.1016/j.trc.2017.04.011

Matthews, B.; Evangelinos, C.; Johnson, D.; Meunier, D. 2009. Impacts and incentives of differentiated rail infrastructure charges in Europe - focus on freight, European Transport 1 Trasporti Europei 43: 83-112.

Milgrom, P. 2004. Putting Auction Theory to Work. Cambridge University Press. 396 p. https://doi.org/10.1017/CBO9780511813825

Nash, C. 2005. Rail infrastructure charges in Europe, Journal of Transport Economics and Policy 39(3): 259-278.

Nilsson, J.-E. 2015. Congestion and scarcity in scheduled transport modes, in C. Nash (Ed.). Handbook of Research Methods and Applications in Transport Economics and Policy, 134-153. https://doi.org/10.4337/9780857937933.00014

Nilsson, J.-E. 2002. Towards a welfare enhancing process to manage railway infrastructure access, Transportation Research Part A: Policy and Practice 36(5): 419-436. https://doi.org/10.1016/S0965-8564(01)00011-8

Osborne, M. J. 2004. Publicly-Available Solutions for an Introduction to Game Theory. University of Toronto, Canada. 87 p.

Pachl, J. 2009. Railway Operation and Control. VTD Rail Publishing. 255 p.

Peña-Alcaraz, M. 2015. Analysis of Capacity Pricing and Allocation Mechanisms in Shared Railway Systems. PhD Dissertation. Massachusetts Institute of Technology, US. 194 p. Available from Internet: http://dspace.mit.edu/handle/1721.1/99564

Perennes, P. 2017. Open Access for Rail Passenger Services in Europe: lesson learnt from forerunner countries, Transportation Research Procedia 25: 358-367. https://doi.org/10.1016/j.trpro.2017.05.413

Perennes, P. 2014. Use of combinatorial auctions in the railway industry: can the "invisible hand" draw the railway timetable?, Transportation Research Part A: Policy and Practice 67: 175-187. https://doi.org/10.1016/j.tra.2014.07.002

Quinet, E. 2003. Short term adjustments in rail activity: the limited role of infrastructure charges, Transport Policy 10(1): 73-79. https://doi.org/10.1016/S0967-070X(02)00047-1

Rassenti, S. J.; Smith, V. L.; Bulfin, R. L. 1982. A combinatorial auction mechanism for airport time slot allocation, The Bell Journal of Economics 13(2): 402-417. https://doi.org/10.2307/3003463

Schlechte, T. 2012. Railway Track Allocation: Models and Algorithms. Dissertation. Technical University of Berlin, Germany. 244 p. Available from Internet: http://www.zib.de/schlechte/phdthesis.pdf

Stern, J.; Turvey, R. 2003. Auctions of capacity in network industries, Utilities Policy 11(1): 1-8. https://doi.org/10.1016/S0957-1787(02)00062-0

Talebian, A.; Zou, B.; Peivandi, A. 2018. Capacity allocation in vertically integrated rail systems: A bargaining approach,
Transportation Research Part B: Methodological 107: 167-191. https://doi.org/10.1016/j.trb.2017.12.001

Woodburn, A. 2014. Development of rail freight in Europe: What Regulation Can and Cannot Do: United Kingdom Case Study. Centre on Regulation in Europe (CERRE), Brussels, Belgium. 43 p. Available from Internet: http://www.cerre.eu/sites/cerre/ files/141211_CERRE_RailFreight_UK_Case_Study_Final.pdf 